\title{
Suscetibilidade da linhagem de células Vero a cepas vacinais do vírus do sarampo
}

\author{
Susceptibility of Vero cell line to vaccine strains of the measles virus
}

\author{
Célia Sayoko Takata*, Flávia Saldanha Kubrusly*, Cosue Miyaki*, Inácio França Mendes*, Edda de Rizzo**
}

TAKATA, C.S. et al. Suscetibilidade da linhagem de células Vero a cepas vacinais do vírus do sarampo. Rev. Saúde Pública, 28: 209-12, 1994. A suscetibilidade da linhagem de células Vero ao vírus do sarampo é bem conhecida e sua utilização no controle da potência da vacina contra o sarampo é amplamente difundida. Com o objetivo de comparar a suscetibilidade de células Vero empregadas em titulações, amostras provenientes de dois laboratórios controladores (Vero IB e Vero INCQS), foram testadas frente a três cepas vacinais: Moraten, Schwarz e Biken CAM-70. Foram titulados 72 lotes de vacinas contra o sarampo, sendo 25 produzidos com a cepa Moraten, 24 com a cepa Schwarz e 23 com a cepa Biken CAM70. A análise estatística dos resultados obtidos nas titulações, feita através dos testes Limites para uma Média e " $t$ " de Student, mostrou que para as cepas Moraten e Biken CAM-70, as diferenças de títulos não foram estatisticamente significantes, o mesmo não ocorrendo com a cepa Schwarz, para a qual as células Vero IB se mostraram mais sensíveis.

Descritores: Vacina contra sarampo, normas. Vírus do sarampo, imunologia. Suscetibilidade celular.

\section{Introduçăo}

O teste de potência da vacina contra o sarampo tem por objetivo constatar se o vírus nela contido está presente em concentração capaz de ativar os mecanismos imunitários do indivíduo vacinado, de modo que anticorpos específicos possam posteriormente protegêlo de uma infecção natural pelo vírus do sarampo. Essa concentração pode variar de acordo com a cepa vacinal $^{6,8}$.

Desde a descoberta de Enders e Peebles ${ }^{1}$ de que o vírus do sarampo causava efeito citopatogênico específico em culturas de células, vários sistemas celulares têm sido utilizados para o seu estudo, isolamento, propagação e titulação ${ }^{4,12}$, como por exemplo, células primárias ou de linhagens originárias de diferentes animais, principalmente de símios. O grau de suscetibilidade dessas células não é o mesmo para as diferentes cepas de vírus, ou para aquelas derivadas da mesma cepa viral mas com histórico de atenuação diferente ${ }^{4}$, pois o próprio cultivo de células animais in vitro, por períodos longos de tempo, pode, às vezes, provocar ampla variação de suas características ou de seus componentes.

\footnotetext{
* Serviço de Culturas Celulares do Instituto Butantan - São Paulo, SP - Brasil

** Serviço de Virologia do Instituto Butantan - São Paulo, SP - Brasil

Separatas/Reprints: C.S.Takata - Av. Vital Brasil, 1500 - Butantan - 05503-900 - São Paulo, SP - Brasil

Edição subvencionada pela FAPESP. Processo 94/0500-0.
}

A linhagem de células Vero 9,13 , originária de rim de macaco Cercopithecus aethiops (African green monkey), é usada em caráter de rotina por laboratórios de controle de qualidade que monitoram a potência de vacinas contra o sarampo ${ }^{3,5}$. No presente estudo, a suscetibilidade de duas amostras de células Vero foi avaliada frente a três cepas vacinais do vírus do sarampo: Moraten, Schwarz e Biken CAM-702,14,16. O objetivo foi verificar a variabilidade de resultados obtidos nos testes de potência realizados por laboratórios controladores, mesmo quando utilizam a mesma metodologia de titulação.

\section{Material e Método}

Células de linhagem Vero - Células Vero, originalmente obtidas do ATCC (American Type Culture Collection) e provenientes de dois centros controladores de qualidade de vacina contra o sarampo foram usadas nas titulações de potência: a) Vero IB* utilizada nas passagens 200 a 250 e mantida em Eagle MEM modificado $^{10}$ (Eagle/1) acrescido de $10 \%$ de soro de vitela; b) Vero INCQS** utilizada nas passagens 49 a 84 e mantida em Eagle MEM (Flow Laboratories, CAT 10.101) (Eagle/2) suplementado com 5\% de soro fetal bovino. Nos testes, a concentração das células

\footnotetext{
* IB - Serviço de Culturas Celulares - Instituto Butantan São Paulo.

** INCQS - Instituto Nacional de Controle de Qualidade em Saúde - Rio de Janeiro.
} 
Vero IB foi de $3 \times 10^{5}$ células $/ \mathrm{ml}$ em Eagle $/ 1+2 \%$ de soro de vitela, enquanto que a concentração das célu-

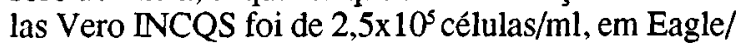
$2+5 \%$ de soro fetal bovino.

Vacinas contra o sarampo - Foi titulada a potência de 72 lotes de vacina contra o sarampo obtidos no Suprimento II, órgão da Secretaria de Estado da Saúde de São Paulo. No total foram titulados 25 lotes produzidos com a cepa Moraten, 24 com a cepa Schwarz e 23 com a cepa Biken CAM-70.

Teste de potência - Foi realizado por microtitulação, de acordo com o protocolo seguido pelos dois centros de controle dos quais provieram as duas amostras de células Vero. De cada lote de vacina foi feito um pool de dois frascos do qual foi retirada uma alíquota que foi diluída ao décimo, em paralelo, em meios Eagle/1 e Eagle/2, e em duplicata. Em dez orifícios de placas de microtitulação de 96 orifícios de fundo chato, inoculou-se $0,1 \mathrm{ml}$ de cada diluição, sendo em seguida adicionado $0,1 \mathrm{ml}$ de suspensão de células Vero (IB ou INCQS). Em cada placa foram incluídos controles de meio e de células. As placas foram incubadas a $36,5^{\circ} \mathrm{C}$ e após 7 dias, foi realizada a leitura do efeito citopatogênico (ECP). Os títulos calculados pelo método de Karber ${ }^{15}$, representam a média dos títulos das duplicatas e foram expressos em
$\mathrm{DICC}_{50}$ (dose infectante de cultura de células 50\%) por dose de $0,5 \mathrm{ml}$.

Virus sarampo-padrão - Cepa Schwarz - Aconstância da potência relativa do vírus foi monitorada em todos os testes, através da inclusão de um vírus sarampo-padrão, lote-trabalho, produzido no Serviço de Culturas Celulares do Instituto Butantan ${ }^{11}$.

Análise estatística - A análise estatística foi feita através da comparação de médias de dados pareados com os testes Limites para uma Média (determinação de intervalos de confiança para a medianapopulacional) e " $t$ " de Student, utilizando-se o nível de significância de 5\% para ambos os testes?.

\section{Resultados e Discussáo}

Cada resultado obtido na titulação dos 72 lotes de vacina contra o sarampo, utilizando duas amostras de células Vero, constitui a média dos títulos das duplicatas, os quais não diferiram mais do que $0,3 \log _{10}$

Como a simples análise dos resultados apresentados na Tabela poderia sugerir maior sensibilidade das células Vero INCQS à cepa Moraten, ou das células Vero IB com relação às cepas Schwarz e Biken CAM70. esses dados foram submetidos a testes estatísticos,

Tabela. Resultados das titulaçōes de vacinas contra o sarampo, cepas Moraten, Schwarz e Biken CAM-70, em células Vero IB e Vero INCQS $\left(\log _{10} \operatorname{DICC}_{50} 10,5 \mathrm{ml}\right)$.

\begin{tabular}{|c|c|c|c|c|c|c|}
\hline \multirow{4}{*}{ Lote } & \multicolumn{5}{|c|}{ Vacinas contra o Sarampo } & \\
\hline & \multicolumn{2}{|c|}{ Moraten } & \multirow{2}{*}{\multicolumn{2}{|c|}{$\begin{array}{l}\text { Schwarz } \\
\text { élulas Vero }\end{array}$}} & \multicolumn{2}{|c|}{ Biken } \\
\hline & & & & & & \\
\hline & IB & INCQS & $\mathrm{IB}$ & INCQS & IB & INCQS \\
\hline $\begin{array}{r}1 \\
2 \\
3 \\
4 \\
5 \\
6 \\
7 \\
8 \\
9 \\
10 \\
11 \\
12 \\
13 \\
14 \\
15 \\
16 \\
17 \\
18 \\
19 \\
20 \\
21 \\
22 \\
23 \\
24 \\
25\end{array}$ & $\begin{array}{l}4,00 \\
3,75 \\
3,95 \\
3,80 \\
3,70 \\
4,05 \\
4,15 \\
3,95 \\
4,10 \\
3,80 \\
4,40 \\
3,95 \\
4,10 \\
3,65 \\
3,85 \\
3,35 \\
3,90 \\
3,85 \\
3,85 \\
3,75 \\
3,55 \\
3,85 \\
3,75 \\
3,60 \\
4,15\end{array}$ & $\begin{array}{l}4,35 \\
3,55 \\
4,25 \\
3,95 \\
3,80 \\
4,20 \\
4,25 \\
4,15 \\
4,15 \\
4,00 \\
4,30 \\
4,10 \\
4,10 \\
3,75 \\
3,40 \\
3,55 \\
4,25 \\
3,85 \\
3,75 \\
4,05 \\
3,65 \\
3,90 \\
3,30 \\
3,30 \\
4,45\end{array}$ & $\begin{array}{r}4,35 \\
3,95 \\
3,85 \\
3,85 \\
3,75 \\
3,90 \\
4,00 \\
3,35 \\
3,60 \\
3,65 \\
3,85 \\
3,75 \\
3,80 \\
3,85 \\
3,90 \\
3,30 \\
3,70 \\
3,95 \\
3,30 \\
3,40 \\
3,35 \\
3,45 \\
3,50 \\
4,48 \\
-\end{array}$ & $\begin{array}{l}4,00 \\
3,80 \\
3,50 \\
3,80 \\
3,75 \\
3,55 \\
3,75 \\
3,40 \\
3,85 \\
3,45 \\
3,80 \\
3,70 \\
3,65 \\
3,85 \\
3,70 \\
3,55 \\
3,60 \\
4,10 \\
3,10 \\
3,30 \\
3,40 \\
3,30 \\
3,50 \\
4,05 \\
-\end{array}$ & $\begin{array}{l}4,50 \\
4,30 \\
4,10 \\
4,75 \\
3,95 \\
4,00 \\
3,70 \\
3,40 \\
3,40 \\
3,85 \\
3,15 \\
3,50 \\
3,50 \\
3,55 \\
3,40 \\
3,90 \\
3,70 \\
4,30 \\
3,60 \\
4,00 \\
3,25 \\
3,70 \\
3,65 \\
- \\
4\end{array}$ & $\begin{array}{l}4,85 \\
4,20 \\
4,30 \\
4,80 \\
4,45 \\
3,70 \\
3,80 \\
3,30 \\
3,20 \\
3,50 \\
2,85 \\
2,95 \\
3,70 \\
3,50 \\
3,20 \\
4,00 \\
3,55 \\
4,45 \\
3,45 \\
3,55 \\
3,00 \\
3,25 \\
3,35 \\
- \\
.\end{array}$ \\
\hline $\begin{array}{c}\text { Média } \\
\text { desvio - padrāo }\end{array}$ & $\begin{array}{c}3,87 \\
0,218\end{array}$ & $\begin{array}{c}3,93 \\
0,327\end{array}$ & $\begin{array}{c}3,74 \\
0,300\end{array}$ & $\begin{array}{c}3,64 \\
0,245\end{array}$ & $\begin{array}{c}3,79 \\
0,398\end{array}$ & $\begin{array}{c}3,69 \\
0,564\end{array}$ \\
\hline
\end{tabular}


a fim de verificar se as diferenças observadas entre os títulos obtidos eram ou não significantes.

No teste Limites para uma Média, os valores dos intervalos de confiança foram $-0,153$ e 0,029 para a cepa Moraten; 0,025 e 0,174 para a Schwarz; e -0,016 e 0,211 para a Biken CAM-70. Os intervalos de confiança que incluíram o zero, como os das cepas Moraten e Biken CAM-70, demonstraram que as diferenças das médias dos títulos obtidos com as duas amostras de células Vero, não foram estatisticamente significantes. Por outro lado, a cepa Schwarz apresentou números que indicaram ser a diferença dos valores obtidos nas titulaçð̃es realizadas em células Vero IB e INCQS, estatisticamente significante (o intervalo não incluiu o zero). No teste " $t$ " de Student, os valores para $t$ e $t_{\text {críico }}\left(t_{c}\right)$ encontrados foram $t=1,382$ para a cepa Moraten $\left(t_{c}=2,06\right), t=2,697$ para a cepa Schwarz $\left(t_{c}=2,06\right)$ e $t=1,746$ para a cepa Biken CAM-70 $\left(t_{c}=2,07\right)$. De acordo com estes resultados, apenas a cepa Schwarz apresentou diferenças de título estatisticamente significantes com $o$ valor de $t>t_{c}$, confirmando os resultados do teste anterior.

Os resultados dos testes estatísticos demonstraram suscetibilidade semelhante das células Vero IB e INCQS em relação às cepas Moraten e Biken CAM-70 e para a cepa Schwarz foi verificada uma maior suscetibilidade das células Vero IB. O conjunto destes dados permitiu comprovar que a sensibilidade de linhagens celulares com relação às cepas virais $2,14,16$, ou a virus derivados de uma mesma cepa ${ }^{4}$, embora com histórico de passagens seriadas diferente, pode variar. Além disso, deve-se ainda considerar que, embora tendo a mesma origem (ATCC), as duas amostras de células Vero usadas nos dois laboratórios, haviam sido mantidas em meios de cultura e soros diferentes, de acordo com protocolos próprios de manutenção, o que poderia ter colaborado para o aparecimento das diferenças de sensibilidade observadas neste estudo

Desse modo, sugere-se que os laboratórios controladores de vacina contra o sarampo deveriam utilizar não apenas o mesmo substrato celular, mas padronizar os protocolos seguidos para a sua manutenção, bem como a metodologia de titulação, a fim de minimizar as diferenças de resultados eventualmente verificadas que poderiam gerar controvérsias com relação à potência da vacina.

\section{Agradecimentos}

Ao Prof. Dr. Carlos Alberto de Bragança Pereira, do Instituto de Matemática e Estatística da Universidade de São Paulo, pela orientação na análise estatística dos resultados; ao Setor de Vacinas- Suprimento II da Secretaria de Estado da Saúde de São Paulo, pelo fornecimento das vacinas usadas na pesquisa.
TAKATA, C.S. et al. [Susceptibility of Vero cell line to vaccine strains of the measles virus]. Rev. Saúde Pública, 28: $209-12,1994$. Vero cells used by distinct measles vaccine control laboratories had their susceptibility to Moraten, Schwarz and Biken CAM-70 vaccine strains assayed. Of a total of 72 lots of measles vaccine whose potency was titrated by microtechnique in two Vero cell samples (Vero IB and Vero INCQS), 25 had been produced with Moraten strain, 24 with Schwarz and 23 with Biken CAM-70. The statistical analysis of the results demonstrated that both Verocells assayed presented comparable susceptibility to Moraten and Biken CAM-70 strains. As to the Schwarz strain, Vero IB cells were more susceptible than the other cell sample tested, thus confirming the existence of different sensitivities of Vero cells to some measles vaccine strains, or even to viruses derived from the same strain but with different passage histories. An altered cell susceptibility to virus replication may significantly alter the results in potency testing. Such alteration may be caused not only by the adoption of distinct protocols for the maintenance of cell cultures by different control laboratories but also by the methodology followed in the vaccine titration. In order to minimize the differences existing among the results obtained in the potency testing, it is suggested that all control laboratories should use the same protocols for cell culture maintenance as well as for vaccine potency testing.

Keywords: Measles vaccine, standards. Measles virus, immunology.Cell susceptibility.

\section{Referências Bibliográficas}

1. ENDERS, J.F.\& PEEBLES, T.C.Propagation in tissue cultures of cytopathogenic agents from patients with measles. Proc. Soc.Exp. Biol. Med., 86: 277-86, 1954.

2. HILLEMAN,M.R.;BUYNAK,E.B.; WEIBEL,R.E.; STOKES, J.; WHITMAN JR., J.E.; LEAGUS, M.B. Development and evaluation of the Moraten measles virus vaccine.JAMA, 266: $587-90,1968$

3. KENNY, M.T. \& SCHELL, K. Microassay of measles and mumps virus and antibody in Vero cells.J.Biol. Standard., 3: 291-303, 1975 .

4. MATUMOTO, M. Multiplication of measles virus in cell cultures. Bacteriol. Rev., 30: 152.76, 1966.

5. MENDES, I.F.; TAKATA, C.S.; KUBRUSLY, F.S.; MIYAKI, C.; TENÓRIO,E.C.N.; FANG,F.L.W;CHAVES,M.M.G.; RIZZO, E. de. Statistical comparison of the micro and macro techniques in the assessment of the measles vaccines potency testing. In: $5^{9}$ Encontro Nacional de Virologia. Resumos. p. 253. São Lourenço, MG, 1990.

6. MEYER, H.M.; BROOKS, B.E.; ROGERS, N.G. Potency testing of live measles vaccine. Ant.J. Dis. Child., 103: 4579,1962 .

7. NOETHER, G. E. Introdução à estatística: uma abordagem näo paramétrica. $2^{3} \mathrm{ed}$. Rio de Janeiro, Guanabara Dois, 1983.

8. REQUIREMENTS for measles vaccine (live). In: WHO Experts Committee on Biological Standardization, Geneva, 1987. Geneva, World Health Organization, 1988. p. 93 132. (WHO- Technical Report Series, 771).

9. RHIM, J.S.; SCHELL, K.; CREASY, B.; CASE, W. Biological characteristics and viral susceptibility of an African Green Monkey Kidney cell line (Vero). Proc. Soc. Exp. Biol. Med., 132: 670-8, 1962.

10. RIZZO, E. de; TUCHIYA, H.N.; MARTINEZ, C.H. Técnicas básicas de cultura celular. São Paulo, Instituto Butantan/ Instituto Adolfo Lutz, p. 133, 1983.

11.RIZZO, E. de; TENÓRIO, E.C.N.; MENDES, I.F.; FANG, F.L.W.; PRAL, M.M.; TAKATA, C.S.; MIYAKI, C.; 
GALLINA, N.M.F.; TUCHIYA, H.N.; AKIMURA, O.K. Sorbitol-gelatin and glutamic acid-latose solutions as stabilizers of reference measles virus preparations. Bol. Oficina Sanit. Panam., 105: 45-52, 1988.

12. RUCKLE, G. Studies with measles virus. I. Propagation in different tissue culture systems. J Immunol., 78: $330-40$, 1957.

13. SASAKI, K.; MAKINO, S.; KASAHARA,S. Studies on measles virus. II. Propagation in two established simian renal cell lines and development of a plaque assay. Kitasato Arch.Exp.Med., 37: 27- 42, 1964.

14. TAKAKU, K.; SASADA, T.; KONOBE, T.; ONISAHI, K.; UEDA, S.; TAKAHASHI, M.; MINEKAWA, Y,; OGINO, T.; SUZUKI, N.; YAMANISHI, K.; BABA, K.; OKUNO, $Y$. Studies on further attenuated live measles vaccine. III.
Selection of less reactive variants of CAM measles virus. Biken J., 13: 163-8, 1970.

15. SCHMIDT, N.J. \& EMMONS, R.W. General principles of laboratory diagnostic methods for viral, rickettsial and chlamydial infections. In: Schmidt, N. J. \& Emmons, R.W eds. Diagnostic procedures for viral, rickettsial and chlamydial infections. Washington, D.C., American Public Health Association, 1989. p.1-35.

16. SCHWARZ, A.J.F. Preliminary tests of a highly attenuated measles vaccine. Am. J. Dis. Child., 103: 386-9, 1962.

Recebido para publicação em 12.5 .1993

Reapresentado em 23.11.1993

Aprovado para publicação em 24.3.1994 